\title{
Powdery Mildew of Inula britannica var. chinensis in Korea
}

\author{
Mi-Jeong Park ${ }^{1}$, Kyung-Sook Han ${ }^{2}$, Seung-Beom Hong ${ }^{3}$ and Hyeon-Dong Shin ${ }^{1 *}$ \\ ${ }^{1}$ Division of Environmental Science and Ecological Engineering, Korea University, Seoul 136-701, Korea \\ ${ }^{2}$ Horticultural \& Herbal Environment Division, National Institute of Horticultural and Herbal Science, Suwon 441-440, Korea \\ ${ }^{3}$ National Agrobiodiversity Center, National Academy of Agricultural Science, Suwon 441-707, Korea
}

(Received on October 29, 2009; Accepted on December 1, 2009)

Inula britannica var. chinensis (syn. Inula japonica), called GeumBul-Cho in Korean, is a perennial herb with yellow flowers, native to East Asia including Korea. It has been cultivated or gathered for medicinal purposes in China and Korea. Recently planting of wild flowers along roads and in gardens has become popular in Korea and new businesses have developed to provide seedlings. Dense planting of this plant in nurseries and also in gardens has resulted in powdery mildew infections since 1990 in Suwon and other areas of Korea (Shin, unpublished). Though the morphological characteristics of the fungus were concordant to those of the genus Golovinomyces, its accurate identification could not be made due to absence of the teleomorphic state. In September 2009, formation of the chasmothecia on the infected leaves was found in the garden of National Institute of Horticultural and Herbal Science, Suwon, for the first time in Korea.

White superficial colonies developed amphigenously on leaves and stems (Fig. 1A \& B). Chasmothecia were formed abundantly, especially on the lower leaf surface. Conidiophores were 110$180 \times 10-12.5 \mu \mathrm{m}$, straight at the base, producing conidia in chains with sinuate edge-line. Conidia were ellipsoid to barrel-shaped, 32$38 \times 16-20 \mu \mathrm{m}$, without conspicuous fibrosin bodies. Chasmothecia were $90-120 \mu \mathrm{m}$ in diam., blackish brown, depressed globose. Appendages were about 10-25 in number, mycelioid, curved to tortuous, olivaceous brown throughout or paler upwards, 0-5septate. Asci were 6-14 per chasmothecium, 55-75 $\times 30-42 \mu \mathrm{m}, 2-$ spored. Ascospores were ellipsoidal to oval, $18-28 \times 12.5-17.5 \mu \mathrm{m}$ (Fig. 1C). Based on these morphological characteristics, this fungus was identified as Golovinomyces cichoracearum (DC.) V.P. Heluta (Braun, 1987). To confirm the identification, the ITS region of rDNA was amplified and sequenced, and the resulting sequence was

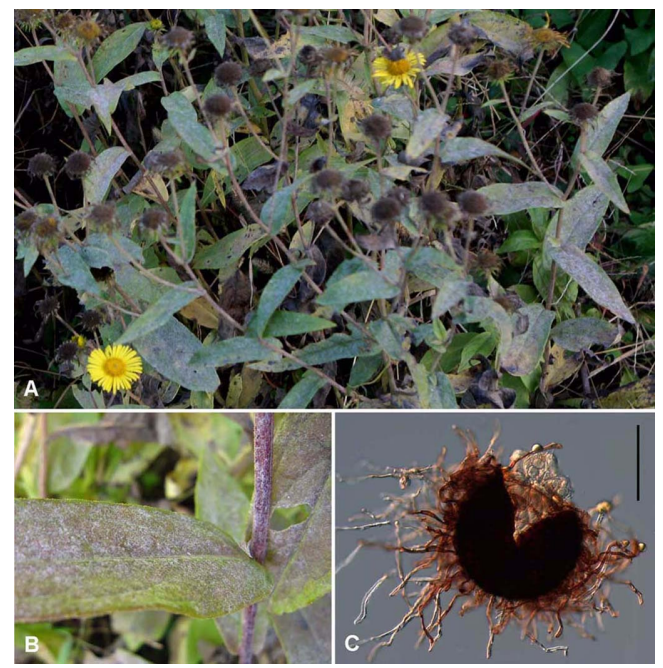

Fig. 1. (A) Heavy infections of powdery mildew on Inula britannica var. chinensis. (B) Close-up of symptoms on leaves and stems. (C) Chasmothecium of Golovinomyces cichoracearum producing several asci with two ascospores each. Bar $=100 \mu \mathrm{m}$. deposited in GenBank (Accession No. GU143089). Molecular phylogenetic reconstructions were performed using MEGA4, version 4.0 for neighbor-joining (using Tajima-Nei distances). Comparison with the sequences available in the GenBank database revealed that the ITS sequence shares $94 \%$ similarity with those of G. cichoracearum parasitic on the hosts belonging to the Heliantheae. In the phylogenetic tree (Fig. 2), the Korean isolate was nested within G. cichoracearum clade (cf. Matsuda and Takamatsu, 2003).

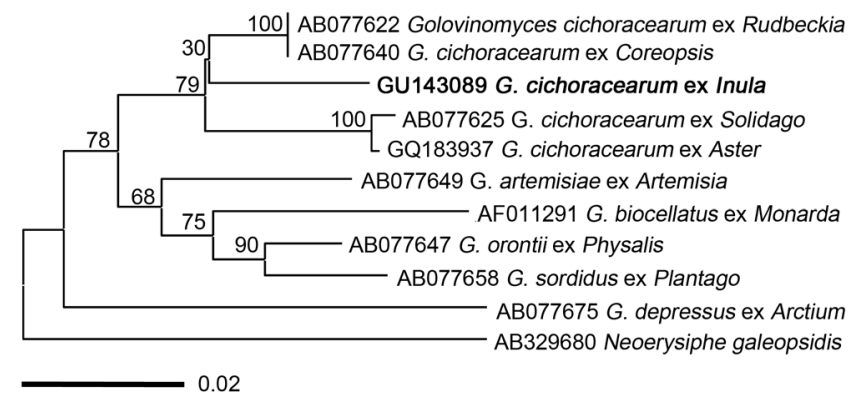

Fig. 2. Phylogenetic relationship between Golovinomyces cichoracearum on Inula britannica var. chinensis and other Golovinomyces species, inferred by neighbor-joining method using the ITS rDNA region. Numbers above the branches represent the bootstrap values. Bar $=$ Number of nucleotide substitutions per site.

The powdery mildew disease of Inula britannica associated with G. cichoracearum has been recorded from most parts of Europe (Farr and Rossman, 2009). In Japan, the powdery mildew on $I$. britannica var. chinensis was identified as G. cichoracearum, based on its anamorphic state in 1951 (cf. Nomura, 1997), and no further records of the disease have been published. To our knowledge, this is the first report of G. cichoracearum infections of I. britannica var. chinensis in Korea. This disease seems not to be a serious threat to the health of established plants. Severe outbreaks of powdery mildew as found in Hongcheon in 2008 and Suwon in 2009 can greatly detract from the beauty of this native plant in landscape plantings.

\section{References}

Braun, U. 1987. A Monograph of the Erysiphales (Powdery Mildews). Beihefte zur Nova Hedwigia 89:1-700.

Farr, D. F. and Rossman, A. Y. 2009. Fungal Databases, Systematic Mycology \& Microbiology Laboratory, ARS, USDA. Retrieved October 24, 2009, from http://nt.ars-grin.gov/fungaldatabases/.

Matsuda, S. and Takamatsu, S. 2003. Evolution of host-parasite relationships of Golovinomyces (Ascomycete: Erysiphaceae) inferred from nuclear rDNA sequences. Mol. Phylogen. Evol. 27:314-327.

Nomura, Y. 1997. Taxonomical Study of Erysiphaceae of Japan. Yokendo Ltd., Tokyo, Japan. 281 pp. (in Japanese)

*Corresponding author (hdshin@korea.ac.kr) 